\title{
choer
}

\section{A Polícia Comunitária do Ceará e o acompanhamento às vítimas de violência}

\author{
Kelyane Silva de Sousa \\ Mestra em Políticas Públicas e Sociedade pela Universidade \\ Estadual do Ceará - UECE \\ Pesquisadora do Observatório da Violência Contra a Mulher \\ OBSERVEM da UECE \\ kelyane.sousa@uece.br \\ https://orcid.org/0000-0002-2871-1504
}

\section{Maria Helena de Paula Frota}

Doutora em Sociologia pela Universidade de Salamanca

Professora do Programa de Pós-Graduação em Políticas Públicas

(PPGPP) da UECE

helenapfrota@gmail.com

https://orcid.org/0000-0002-3327-146X

\section{Raysa Hellen Lopes da Costa}

Graduada em Serviço Social pela Universidade Estadual do Ceará

UECE

lopesrh@yahoo.com

https://orcid.org/0000-0003-3775-0481

\section{Resumo}


com 5 profissionais de segurança pública que fazem parte da UNISEG 4; eles relataram experiências do trabalho da equipe ocorridas durante a pandemia no ano de 2020

Palavras-chave violência contra a mulher; segurança pública; polícia comunitária; COVID-19.

\title{
The Ceará State Community Police and assistance to victims of violence
}

\begin{abstract}
Violence against women has a high incidence in Fortaleza, Ceará, Brazil, and it is regarded as a serious violation of human rights. Law No. 11,340/2006, known as Maria da Penha Act, is considered by the United Nations (UN) as one of the three best legislations in the world aimed at tackling violence against women. Thus, the Ceará State Military Police (Polícia Militar do Estado do Ceará [PMCE]) provides a protection and care service for women experiencing domestic and family violence, named as Support Group for Victims of Violence (Grupo de Apoio às Vítimas de Violência [GAVV]). This study aimed to learn about the work of this group in the Fortaleza neighborhoods of Siqueira, Bom Jardim, and Granja Lisboa, where the 4th Integrated Security Unit (4⿳亠口冋口idade Integrada de Segurança [UNISEG 4]) is located during the Coronavirus Disease 2019 (COVID-19) pandemic. The study had a qualitative nature and used bibliographic, documentary, and field research techniques. Data collection took place through semi-structured interviews conducted with 5 public security professionals from the UNISEG 4; they reported team work experiences during the pandemic in the year 2020.
\end{abstract}

Key words violence against women; public security; community police; COVID-19.

\section{La Policía Comunitaria del Estado de Ceará y la asistencia a víctimas de violencia}

\section{Resumen}

La violencia contra las mujeres tiene una alta incidencia en Fortaleza, Ceará, Brasil, y se considera una grave violación de los derechos humanos. La Ley No. 11.340/2006, conocida como Ley Maria da Penha, es considerada por la Organización de las Naciones Unidas (ONU) como una de las tres mejores legislaciones del mundo destinadas a combatir la violencia contra las mujeres. En ese sentido, la Policía Militar del Estado de Ceará (Polícia Militar do Estado do Ceará [PMCE]) brinda un servicio de protección y atención a mujeres en situación de violencia doméstica y familiar, denominado Grupo de Apoyo a Víctimas de Violencia (Grupo de Apoio às Vítimas de Violência [GAVV]). Este estudio tuvo como objetivo conocer el trabajo de este grupo en los barrios Siqueira, Bom Jardim y Granja Lisboa en Fortaleza, donde se ubica la $4^{\underline{a}}$ Unidad Integrada de Seguridad (4aㅗ Unidade Integrada de Segurança [UNISEG 4]) durante la pandemia de la Coronavirus Disease 2019 (COVID-19). El estudio tuvo carácter cualitativo y utilizó técnicas de investigación bibliográfica, documental y de campo. La recolección de datos se realizó mediante entrevistas semi-estructuradas realizadas a 5 profesionales de seguridad pública de la UNISEG 4; ellos informaron experiencias de trabajo en equipo durante la pandemia en el año 2020.

Palabras clave violencia contra la mujer; seguridad pública; policía comunitaria; COVID-19. 


\title{
La Police Communautaire de l’État du Ceará et l'assistance aux victimes de violence
}

\begin{abstract}
Résumé
La violence contre les femmes a une incidence élevée à Fortaleza, Ceará, Brésil, et est considérée comme une grave violation des droits humains. La Loi No. 11.340/2006, connue sous le nom de Loi Maria da Penha, est considérée par l'Organisation des Nations Unies (ONU) comme l'une des trois meilleures législations au monde visant à lutter contre la violence à l'égard des femmes. Ainsi, la Police Militaire de l'État du Ceará (Polícia Militar do Estado do Ceará [PMCE]) fournit un service de protection et de soins aux femmes victimes de violence domestique et familiale, appelé Groupe de Soutien aux Victimes de Violence (Grupo de Apoio às Vítimas de Violência $[G A V V])$. Cette étude visait à connaître le travail de ce groupe dans les quartiers de Siqueira, Bom Jardim et Granja Lisboa à Fortaleza, où se trouve la 4e Unité de Sécurité Intégrée (4a Unidade Integrada de Segurança [UNISEG 4]) pendant la pandémie de Coronavirus Disease 2019 (COVID-19). L'étude était de nature qualitative et utilisait des techniques de recherche bibliographique, documentaire et de terrain. La collecte des données a été réalisée à travers des entretiens semi-structurés menés avec 5 professionnels de la sécurité publique de l'UNISEG 4; ils ont rendu compte des expériences de travail de l'équipe pendant la pandémie en 2020 .
\end{abstract}

Mots-clés violence contre les femmes; sécurité publique; police communautaire; COVID-19.

\section{Introdução}

A violência contra as mulheres decorre de um cenário histórico marcado por extrema submissão, exploração, discriminação e inferiorização diante dos homens. Ao longo de toda a história, marcadamente na gênese do capitalismo, as mulheres foram alvos de discriminação no que tange as relações sociais de gênero, classe e raça/etnia. A compreensão do fenômeno da violência impõe uma análise aprofundada das relações de domínio e poder que acompanharam a construção simbólica dos gêneros feminino e masculino (Freitas, 2017a).

De acordo com a porta voz da Entidade das Nações Unidas para a Igualdade de Gênero e o Empoderamento das Mulheres (ONU Mulheres) no Brasil, Nadine Gasman (2014), "a violência contra a mulher é uma construção social, resultado da desigualdade de força nas relações de poder entre homens e mulheres. É criada nas relações sociais e reproduzida pela sociedade", confirmando a necessidade de compreender como ela surgiu e permaneceu. Vale destacar que, de acordo com o art. $2^{\circ}$ da Lei n. 11.340 (Lei Maria da Penha, 2006):

Toda mulher, independentemente de classe, raça, etnia, orientação sexual, renda, cultura, nível educacional, idade e religião, goza dos direitos fundamentais 
inerentes à pessoa humana, sendo-lhe asseguradas as oportunidades e facilidades para viver sem violência, preservar sua saúde física e mental e seu aperfeiçoamento moral, intelectual e social.

Nesse sentido, a Polícia Militar do Estado do Ceará (PMCE) oferece um serviço de aproximação, cuidado, acolhimento e proteção de mulheres vítimas de violência doméstica e familiar, orientado pela filosofia de polícia comunitária (Freitas, 2017a), por meio do Grupo de Apoio às Vítimas de Violência (GAVV), que trataremos no decorrer deste artigo.

O GAVV faz parte do serviço de prevenção especializada das unidades integradas de segurança (UNISEG). Segundo (Freitas, 2017a), é executado por policiais militares e tem como propósito atender às mulheres vítimas de violência doméstica e familiar, adotando estratégias do exercício de qualificação da autoridade policial e garantias de proteção integrada e assistencial da Lei Maria da Penha (2006). Além disso, o grupo atende idosas vítimas de abandono, crianças em situação de vulnerabilidade social e vítimas de estupro.

Este estudo teve por objetivo geral:

- Conhecer a atuação do GAVV nos bairros Siqueira, Bom Jardim e Granja Lisboa em Fortaleza, onde se localiza a 4a Unidade Integrada de Segurança (UNISEG 4) durante a pandemia de Coronavirus Disease 2019 (COVID-19)'.

Seus objetivos específicos foram:

- Investigar como ocorre o atendimento as vítimas residentes nos bairros onde atua - GAVV da UNISEG 4;

- Mostrar os desafios do grupo;

- Analisar os resultados que o grupo tem apresentado;

- Compreender a articulação com a rede socioassistencial de enfrentamento à violência contra a mulher.

As UNISEG integram um serviço da Polícia Comunitária do Estado do Ceará, constituindo ferramentas de adequação do exercício da autoridade policial relacionadas aos valores garantidos na Constituição da República Federativa do Brasil (Constituição Federal [CF], 1988). Segundo (Freitas, 2017b), trata-se de uma tecnologia imprescindível para as transformações que as forças de segurança precisam incorporar como modelo que garanta as medidas de proteção integrais e assistenciais de que trata a Lei Maria da Penha (2006).

A polícia comunitária também é definida como uma filosofia e uma estratégia organizacional que proporciona uma parceria entre a população e a polícia, com o objetivo de melhorar a qualidade geral de vida na área. A polícia e a comunidade devem trabalhar

1 Segundo a OMS (2020), a COVID-19 é uma doença infeciosa causada pelo coronavírus da síndrome respiratória aguda grave 2 (SARS-CoV-2). 
juntas para identificar e resolver problemas contemporâneos, como crimes contra a propriedade e contra a pessoa, consumo de drogas lícitas e ilícitas, distúrbios psicológicos e psiquiátricos etc.

\footnotetext{
A Polícia Militar do Ceará, absorvendo os valores da Polícia Comunitária, tem empreendido um profundo processo de adequação e inovação de seus serviços de segurança pública, na prospecção de firmar-se como Instrumento de cidadania, assecuratório dos valores democráticos e de direito, projetados pela Constituição de 1988 e diretamente refletidos na legislação extravagante de defesa da mulher (Freitas, 2017b, p. 33).
}

A pesquisa aqui apresentada é fruto de trabalho de conclusão de curso no Bacharelado de Serviço Social da Universidade Estadual do Ceará (UECE). Ela partiu da experiência de membro do GAVV. A cada nova visita ou revista se observou o quanto as mulheres atendidas se encontram vulneráveis e necessitam do apoio da família, dos amigos, da sociedade e do Estado. Os relatos coletados mostram o medo e a insegurança dessas mulheres que, mesmo separadas dos agressores, temem por sua integridade física e a segurança de seus familiares, pois, mesmo com as medidas protetivas, tais agressores continuam fazendo ameaças.

Nas visitas realizadas se constatou, ainda, a desconfiança dessas mulheres quando indagadas sobre os agressores. Foi essa vivência que nos motivou a aprofundar os estudos acerca da violência doméstica que mata cotidianamente as mulheres.

Segundo Gil (2008), a observação constitui elemento fundamental para a pesquisa. Ela apresenta vantagem em comparação a outras técnicas porque "os fatos são percebidos diretamente, sem qualquer intermediação. Desse modo, a subjetividade, que permeia todo o processo de investigação social, tende a ser reduzida". Cabe ressaltar que o estudo respeita a hierarquia e a disciplina da PMCE, os pilares da instituição, uma vez que a pesquisadora é servidora dela.

Todos os dias são veiculadas estatísticas e notícias na mídia sobre os diversos tipos de violência contra a mulher (como o assédio, o abuso psicológico, a tortura, a perseguição, o feminicídio, a agressão por parceiros ou familiares etc.). A violência de gênero é recorrente e está presente nos espaços públicos e privados nas mais variadas formas e intensidades, tendo o assassinato como sua expressão mais grave (Agência Patrícia Galvão, 2016).

Apesar dos índices de violência contra a mulher serem alarmantes (Agência Patrícia Galvão, 2016), muito tem sido feito para reverter tal quadro. A Lei Maria da Penha (2006) trouxe um olhar inovador ao modo de tratar a violência contra a mulher: "ela instituiu um novo paradigma para os(as) profissionais que atuam no sistema de [J]ustiça [C]riminal e 
para os(as) responsáveis pela formulação de políticas públicas" (Centro de Estudos sobre o Sistema de Justiça [CEJUS], 2012).

A Lei Maria da Penha (2006) assumiu grande importância no enfrentamento e na coibição da violência, que passou a ser tratada como um problema de cunho público, necessitando de intervenção estatal em sua resolutividade (Madeira \& Costa, 2012).

É importante que os profissionais da saúde, da segurança pública e da Justiça de todo o país colaborem no debate técnico para garantir a diversidade de boas práticas diante da violência contra a mulher, para minimizar e/ou zerar tais índices.

\section{Metodologia}

Para atingir nosso propósito, recorremos a técnicas de pesquisa qualitativa, lidando com crenças, costumes e valores. A pesquisa social utiliza metodologias qualitativas devido ao fato de pautarem-se por significados que não podem ser traduzidos em gráficos, esquemas ou outros dados quantitativos - apesar de estes serem complementares aos dados qualitativos.

Segundo Godoy (1995), a pesquisa qualitativa envolve a obtenção de dados descritivos sobre pessoas, lugares e processos interativos pelo contato direto do pesquisador com a situação, compreendendo, assim, os fenômenos dos participantes do estudo. A pesquisa qualitativa tem preocupação com o ambiente natural, valorizando o contato direto e prolongado do pesquisador com o tema. No trabalho de campo se utilizam equipamentos como gravadores para realizar registros.

Os resultados apresentados neste estudo são fruto de pesquisa bibliográfica, baseada em material extraído de trabalhos literários, acadêmicos e científicos, além de livros e artigos. Ademais, utilizaram-se técnicas de pesquisa documental, com consulta a anuários, censos e jornais de grande circulação no Estado do Ceará.

Os dados da pesquisa não se excluem, eles se complementam, e a realidade abrangida interage dinamicamente, como explicita Minayo (1994). A metodologia deve ser um instrumental coerente, elaborado. Que seja capaz de encaminhar impasses teóricos para o desafio da prática. A técnica adotada para a coleta de dados foi a observação participante, com registro em diário de campo, aplicada entre março e junho de 2020.

\section{Policiamento comunitário versus policiamento tradicional}

No início do século XX, com as revoltas sociais e o aumento da criminalidade, os governos necessitavam adequar o exercício de suas forças policiais, motivando os estudos sobre a natureza predominantemente repressiva da polícia como elemento potencializador do crescimento do crime. Nesse modelo de relação, quanto mais a polícia reprimia e tratava 
as pessoas como inimigas, mais as pessoas se afastavam da polícia e, consequentemente, mostravam-se contrárias às corporações (Freitas, 2017b) e práticas como: a) mais policiais nas ruas; b) mais viaturas nas ruas; e c) maior repressão aos cidadãos. Isso contribuiu para aumentar a descrença em relação à polícia (Bohn, n.d.).

$O$ policiamento tradicional enfoca o atendimento de ocorrências ou incidentes específicos. A atividade é pontual, não se trata de uma ação eficiente para solucionar o problema de modo pleno. Ao serem informados de uma situação emergencial, os policiais devem chegar o mais rápido possível ao local, resolver o eventual problema e retornar aos seus postos, ficando novamente disponíveis para outras solicitações (Núcleo de Estudos da Violência da Universidade de São Paulo [NEV USP], 2009).

Com o processo de redemocratização do Brasil, com a abertura política e com a promulgação da CF (1988), as instituições responsáveis pela segurança pública receberam o dever de reformarem-se para atender às novas demandas de cidadania da sociedade. A polícia entrou na agenda política de muitos governantes, pois houve certa falência do policiamento tradicional, pautado por práticas autoritárias. Assim, surgiram diversas discussões acadêmicas, debates políticos e argumentações populares (Bohn, n.d.).

\footnotetext{
Deste modo, estudiosos relataram que o modelo policial que estava sendo utilizado, além de não ser capaz de atender à demanda de crimes, estimulava as pessoas a tomarem atitudes antissociais. Assim sendo, a alternativa proposta pelos relatórios foi a comunitarização da polícia, direcionando o serviço policial para a prevenção. Através do policiamento comunitário haveria uma aproximação entre o policial e a comunidade, aumentando a confiança entre os dois e possibilitando uma mútua cooperação na qual, não só a segurança pública será favorecida, como, também, a melhoria na qualidade de vida no bairro de um modo geral (Freitas, 2017b, p. 43).
}

Com essa estrita relação entre a polícia e a sociedade se iniciou a implementação do policiamento comunitário como uma tentativa de transformar a polícia de controle, repressiva, em uma polícia mais cidadã, humanizada e comprometida com a garantia e a proteção dos direitos humanos (Bohn, n.d.).

\footnotetext{
Enquanto no policiamento tradicional a polícia atua de forma pontual, quando o problema já está colocado, no policiamento comunitário ela atua integrada à comunidade, desenvolvendo um trabalho de prevenção. A prevenção pode ser realizada em dois níveis: Prevenção primária: para impedir o surgimento de um problema de segurança. Prevenção secundária: para evitar que um problema já existente tome grandes proporções, dissemine-se ou cresça (NEV USP, 2009).
} 
Nos países economicamente mais desenvolvidos, a adoção do policiamento comunitário decorreu da constatação de que os modelos de policiamento em vigência não estavam mostrando-se eficazes diante da violência urbana que surgiu no final da década de 1960 e no início da década de 1970. A prática dos policiais para coibir e/ou conter a violência criminal resultou em algumas críticas e, com isso, houve deterioração da imagem das forças policiais junto à população (NEV USP, 2009). "O que a filosofia de polícia comunitária inaugura no Brasil é uma remodelação dos processos de garantia da segurança e da ordem, agora, orientados pelos valores jurídicos assegurados ao povo brasileiro" (Freitas, 2017a).

Quando o Estado não apresenta uma relação de confiança com a população, sua atuação diante dos infratores e da comunidade acaba assumindo formas coercitivas, com uma falsa aparência de aceitação popular enquanto, na verdade, a vítima se sente incomodada e constrangida diante da negação de direitos fundamentais (Freitas, 2017b).

Pensar em mudanças na polícia significa reconhecer que algo não está funcionado bem e precisa ser reformulado. Com o surgimento de novas demandas da cidadania, o Estado democrático vem discutindo o papel da polícia e as práticas de policiamento que visem à garantia de direitos humanos (Bohn, n.d.).

Nesse sentido, o policiamento comunitário (NEV USP, 2009) tem sido implementado em diversos países do mundo como uma evolução do modelo tradicional de polícia (baseado em autoritarismo e atitudes truculentas, como no período do Regime Militar brasileiro) em direção a um modelo de polícia cidadã, próximo à comunidade para romper quaisquer barreiras entre a polícia e os cidadãos (Bohn, n.d.). "O policial, junto à comunidade, além de garantir segurança, deverá exercer função didático-pedagógica, visando a orientar na educação e no sentido da solidariedade social" (Almeida, Moura, \& Freitas, 2017).

Segundo Freitas (2017b), a CF (1988) trouxe o modelo de materialização do Poder Público denominado Estado democrático de direito, no qual a soberania do povo é sua própria razão de ser. O Governo Federal criou o Programa Nacional de Direitos Humanos em 1996 -uma de suas principais propostas era apoiar as experiências de polícia comunitária, que passaram a ser implementadas em todo o Brasil.

A polícia comunitária consiste em uma filosofia organizacional que valoriza a participação da comunidade em suas estratégias de segurança pública. Esta constitui um problema complexo e seu enfrentamento exige participação direta e indireta de todos os grupos que constituem a comunidade à qual se destina a estratégia de segurança.

O NEV USP (2009) apresenta 4 características comuns a esse tipo de policiamento: a) relação de confiança - o policiamento comunitário requer trabalho conjunto entre polícia e população; b) descentralização da atividade policial - esta deve integrar-se à sociedade; c) ênfase nos serviços não emergenciais - atividades orientadas prioritariamente à prevenção 
do crime e à resolução de conflitos; e d) ação integrada entre diferentes órgãos e atores para se adotar um novo olhar diante de problemas de segurança e, ainda, do próprio policial.

Em síntese, de acordo com Almeida, Moura e Freitas (2017) no policiamento tradicional: a) o papel da polícia é preocupar-se com a resolução do crime; b) a polícia se ocupa mais com os incidentes; c) o que determina a eficiência da polícia é o tempo de resposta; d) o policial é o serviço; e) o emprego da força é a técnica adotada para a resolução de problemas. Já na polícia comunitária: a) a polícia é o público e o público é a polícia; b) os policiais são os membros da população pagos para dar atenção em tempo integral às obrigações dos cidadãos; c) a eficácia da polícia é medida pela ausência de crime e de desordem; e d) a polícia se ocupa mais com os problemas e as preocupações dos cidadãos.

Nesse contexto, de acordo com M. G. M. Brasil e Miranda (2011), cabe destacar que a qualificação e a formação dos profissionais de segurança pública passariam a ser orientadas pela ética, pela cidadania e pela educação em direitos humanos. Buscando parcerias com as universidades e outras instituições educacionais, esses seriam os maiores diferenciais dessa nova proposta de formação policial (M. G. M. Brasil \& Miranda, 2011).

Ressalta-se que a polícia comunitária não tem o sentido de assistência policial, mas sim o de participação social. A comunidade deve assumir um papel relevante em sua própria segurança e nos serviços ligados ao bem comum. Vale destacar a necessidade de evitar a interpretação de que se almeja criar uma nova polícia. Além disso, o "Policiamento Comunitário não é uma fórmula mágica ou panaceia" (Alencar, Moura, \& Freitas, 2017), ele não é a solução para os problemas de insegurança pública, ele facilita a aproximação com a sociedade.

\section{A Polícia Militar do Estado do Ceará}

A PMCE tem por missão constitucional o policiamento ostensivo e a preservação da ordem pública. Em 1835, o Presidente (Governador) da Província do Ceará, o padre, senador vitalício e orador sacro José Martiniano de Alencar, assinou a Resolução Provincial n. 13, de 24 de maio de 1835, criando a Força Pública do Ceará, embrião da PMCE. Esta assumiu sua denominação atual em 4 de janeiro de 1947, a partir da entrada em vigor da Constituição dos Estados Unidos do Brasil (Constituição Brasileira, 1946).

Seu primeiro Comandante foi o Tenente do Exército Brasileiro Tomaz Lourenço da Silva Castro, que a comandou de 24/05/1835 a 19/01/1839. No organograma, a PMCE é comandada por um oficial superior do posto de coronel, denominado Comandante-Geral.

A Lei Estadual n. 13.407 (Código Disciplinar da Polícia Militar do Ceará e do Corpo de Bombeiros Militar do Estado do Ceará, 2003) traz em seu art. 8o os deveres éticos que pautam a atividade profissional sob o signo da retidão moral - dentre eles temos: 
IV - servir à comunidade, procurando, no exercício da suprema missão de preservar a ordem pública e de proteger a pessoa, promover, sempre, o bem-estar comum, dentro da estrita observância das normas jurídicas e das disposições deste Código; $\mathrm{V}$ - atuar com devotamento ao interesse público, colocando-o acima dos anseios particulares;

$[\ldots]$

XVIII - proceder de maneira ilibada na vida pública e particular.

Tendo no policiamento ostensivo sua atividade-fim, a instituição está presente em todo o estado com suas diversas unidades e subunidades operacionais distribuídas de modo estratégico. Os mais de 15 mil homens e mulheres do efetivo estão distribuídos em todos os municípios cearenses para servir e proteger o cidadão.

A polícia existe para que seja garantido o exercício de igualdade material das relações sociais. Seu nível de aceitação, influência e autoridade cresce na mesma proporção em que se amplia a participação, o respeito e a confiança da comunidade (Freitas, 2017a).

A PMCE já desenvolve suas práticas operacionais em plena consonância com os princípios norteadores do policiamento comunitário. Conta com diversos voluntários dos Conselhos Comunitários de Defesa Social (CCDS), na capital e no interior, com efetivo engajamento das autoridades policiais de cada comunidade envolvida (Alencar, Moura, \& Freitas, 2017).

\section{O Policiamento Comunitário no Ceará}

A PMCE foi uma das pioneiras no Brasil em termos de integração do policiamento comunitário, sendo implementado no final da década de 1980 e no início da década de 1990. O trabalho obteve uma boa aceitação junto à população e um bom retorno para a instituição, mas o projeto foi encerrado (Alencar, Moura, \& Freitas, 2017).

A partir dos anos 1990, as polícias militares, que tinham como espelho o policiamento praticado no Japão, no Canadá e nos Estados Unidos da América (EUA), passaram a empreender em suas fileiras o desenvolvimento de procedimentos policiais orientados pela doutrina da polícia comunitária (Freitas \& Parente, 2016).

Depois dessa experiência se tentou retomar o policiamento comunitário. $O$ fato de maior repercussão ocorreu quando a PMCE abriu as portas para as lideranças comunitárias - estas não souberam lidar com tamanho poder e usurparam suas atribuições, provocando grande rejeição por parte da tropa, que não estava devidamente preparada para aceitar tal ingerência (Alencar, Moura, \& Freitas, 2017). 
A PMCE assume papel fundamental nesse processo de aperfeiçoamento das políticas públicas. Os direitos que protegem a mulher necessitam que a instituição adote estratégias diferenciadas que se apresentem como sobrepeso para equilibrar as relações desiguais entre os gêneros masculino e feminino (Freitas, 2017a).

Freitas (2017b) ressalta que, apesar de observarem-se movimentos internos em 1980 que apontavam no sentido da polícia comunitária, somente no final de 2007 a PMCE passou por profundas mudanças em seu modelo organizacional, orientadas pela filosofia de polícia comunitária. O então governador do estado, Cid Gomes, lançou o programa de polícia comunitária, o chamado Programa Ronda do Quarteirão, para aproximar a polícia e a comunidade, apresentando o policial militar como garantidor dos valores democráticos de respeito à vida e à dignidade da pessoa humana.

O Programa Ronda do Quarteirão causou grande impacto na oferta tradicional dos serviços de segurança pública e tornou-se amplamente conhecido pela população. Contava com formação específica, inovações tecnológicas, logística arrojada e fardamento diferenciado (Freitas, 2017b). O governo formou um grande número de novos soldados que atuavam nas ruas das principais sedes dos municípios cearenses, aquelas com maior expressividade populacional (Alencar, Moura, \& Freitas, 2017).

O modelo estreado instalava no mesmo território tanto o policiamento que seria orientado pela filosofia de polícia comunitária (Programa Ronda do Quarteirão) quanto aquele pautado pelos valores tradicionais (Policiamento Ostensivo Geral [POG]) (Alencar, Moura, \& Freitas, 2017). Entretanto, vale destacar que houve um enfraquecimento do programa.

Freitas e Parente (2016) afirma que "o Programa Ronda passou a enfrentar as suas primeiras resistências, tanto do público interno, quanto dos difusos usuários do sistema de segurança pública", assim como outras polícias brasileiras sendo, sobretudo, arrastada pelo imediatismo e pela escassez de estudos que apontassem o melhor processo de implantação.

Mostra-se relevante informar que tanto o Programa Ronda do Quarteirão quanto o POG continuam a existir, porém, suas estruturas logísticas, de pessoal e doutrinárias foram comprometidas. Em 2016, o atual governador do Estado do Ceará lançou as UNISEG para tentar superar as dificuldades e contradições que comprometeram o Programa Ronda do Quarteirão (Freitas, 2017b), que abordamos no próximo tópico.

\section{Caracterizando as unidades integradas de segurança}

As UNISEG compõem as ações propostas pelo Decreto Estadual n. 31.840 (Pacto "Por um Ceará Pacífico", 2015), com atuação intersetorial das entidades públicas para construir uma cultura de paz, por meio de tratamento multifocal do fenômeno da violência - não mais compreendido como problema meramente policial (Freitas, 2017b). 
Coordenado pela vice-governadora Izolda Cela, o Pacto "Por um Ceará Pacífico" (2015) tem como propósito a redução dos índices criminais e o aumento da segurança da população cearense, via ações políticas de prevenção social e segurança pública que se articulam à atuação interinstitucional das 3 esferas do Poder Público junto à sociedade civil.

\begin{abstract}
Art. 1 Fica instituído o PACTO "POR UM CEARÁ PACÍFICO", com o objetivo de construir uma Cultura de Paz no território do Estado do Ceará, através da definição, implantação, monitoramento e avaliação contínua de políticas públicas interinstitucionais de prevenção social e segurança pública, para a melhoria do contexto urbano, acolhimento às populações mais vulneráveis e enfrentamento à violência, com atuação articulada, integrada e compartilhada dos órgãos e entidades públicas estaduais, municipais e federais, e da sociedade civil.
\end{abstract}

O Pacto "Por um Ceará Pacífico" (2015) veio para reunir diversos setores da sociedade em um grande movimento pela vida, com organizações não governamentais (ONG), movimentos sociais, associações e entidades profissionais, empresas e todas as pessoas da comunidade. O art. 2ำ do Pacto "Por um Ceará Pacífico" (2015) dispõe que ele será executado por programas, projetos e atividades integradas, nas áreas de segurança pública e defesa social, Justiça e cidadania, direitos humanos, educação, ciência e tecnologia, saúde e política sobre drogas, dentre outras.

A partir do momento em que foi reconhecido que a violência letal é um fenômeno complexo e multifacetado, criou-se o Pacto "Por um Ceará Pacífico" (2015) para exigir o enfrentamento das condições e situações que o impulsionam via articulação de esforços e investimentos em diferentes áreas, combinando ações de prevenção e controle:

\footnotetext{
A construção de uma cultura de paz, longe de almejar a constituição de comunidades nas quais inexiste o conflito social, implica, de fato, a disponibilização e o fortalecimento de canais, técnicas, instâncias e metodologias que sensibilizem e empoderem os cidadãos para o encaminhamento de seus conflitos segundo mecanismos não violentos (Governo do Estado do Ceará, n.d., p. 13).
}

O Pacto "Por um Ceará Pacífico" (2015) foi subsidiado por 3 requisitos fundamentais para que se criasse um programa com resposta positiva de prevenção e redução da violência: 


\begin{abstract}
O primeiro é a observância da relação entre focalização/institucionalização de ações baseadas no tripé: aproximação com a população, uso intensivo de informações e aperfeiçoamento da inteligência e da investigação, e articulação e integração das agências de segurança pública e justiça. [...] Em segundo lugar, encontra-se a articulação do desenho das ações de segurança estrito senso com a realidade do sistema prisional no planejamento estratégico e tático de operações e de metas. [...] Por fim, o Ceará Pacífico é caracterizado por uma arquitetura e um modelo de governança que não são engessados e possibilitam a consolidação de formatos que possam ser redesenhados e que resultem de um processo participativo de construção (Governo do Estado do Ceará, 2015, p. 13).
\end{abstract}

Nesse sentido, Freitas (2017b) afirma que as UNISEG surgiram em um contexto de resgate dos princípios de polícia comunitária inicialmente observados no Programa Ronda do Quarteirão. As UNISEG acrescentam outros princípios que tornem mais prático o significado do direito à segurança pública assegurado pela CF (1988).

Freitas (2017b) afirma que as UNISEG têm como princípios constitutivos: a) a redução territorial das responsabilidades circunscricionais dos órgãos de segurança pública do Estado; b) a existência de uma unidade de comando das forças no território; c) a inovação dos serviços de segurança; e d) a integração dos serviços de segurança pública a outros órgãos dos governos estadual, municipal e federal.

As instituições que fazem parte das iniciativas de segurança pública das UNISEG são: a) PMCE; b) Polícia Civil do Estado do Ceará (PCCE); c) Corpo de Bombeiros Militar do Estado do Ceará (CBMCE); d) Polícia Forense do Estado do Ceará (PEFOCE); e) Academia Estadual de Segurança Pública (AESP); f) outras secretarias estaduais; e g) prefeituras municipais. As UNISEG têm na integração dos órgãos de segurança uma de suas principais características no trato do fenômeno da violência e dos crimes que assolam as comunidades.

Vale destacar que as UNISEG agregam tanto a PCCE, a PMCE e o CBMCE em áreas circunscricionais coincidentes, porém, elas não se encontram na mesma instalação física. Cada instituição tem seu próprio espaço. A PMCE é a força de segurança pública mais presente nas UNISEG.

\title{
Grupo de Apoio às Vítimas de Violência
}

O GAVV é considerado uma inovação nos serviços da PMCE quando relacionados à polícia comunitária. Desenvolve ações de prevenção especializadas e focadas nos grupos considerados mais vulneráveis à violência: a) mulheres; b) crianças; c) idosos; e d) famílias vitimadas por crimes violentos e de letalidade intencional (Freitas, 2017b). Ressalte-se que o atendimento é direcionado, sobretudo, às vítimas de violência doméstica e familiar. 
Os principais objetivos do GAVV são:

a) Dar um sentido prático ao conceito da polícia que identifica, envolve-se, apoia, acompanha e cuida das pessoas com notória vulnerabilidade à violência; b) Potencializar o comprometimento do Sistema de Segurança Pública com a proteção da comunidade; c) Construir uma prática de polícia comunitária com aprofundado relacionamento com a comunidade; d) Fortalecer a presença da polícia em territórios específicos (FREITAS, 2017b, p. 40).

O GAVV da UNISEG 4 atua em uma área historicamente violenta de Fortaleza, cobrindo os bairros Bom Jardim, Granja Lisboa e Siqueira. Sua equipe possui 3 policiais devidamente uniformizados, armados e equipados, que trabalham em viaturas da PMCE de segunda a sexta-feira das 8:00 às 15:00. É obrigatório que a equipe tenha uma policial feminina (PFem). A mulher tende a apresentar maior empatia no atendimento às vítimas, tornando-se interlocutora privilegiada e passando maior confiança às pessoas que atende (Paiva \& Almeida, 2008).

Vale ressaltar a importância de contar com uma mulher na equipe, assim como dispõe o art. 10-A, caput e § 1º, da Lei Maria da Penha (2006):

Art. 10-A. É direito da mulher em situação de violência doméstica e familiar o atendimento policial e pericial especializado, ininterrupto e prestado por servidores - preferencialmente do sexo feminino previamente capacitados.

§ 1ํ A inquirição de mulher em situação de violência doméstica e familiar ou de testemunha de violência doméstica, quando se tratar de crime contra a mulher, obedecerá às seguintes diretrizes: I - salvaguarda da integridade física, psíquica e emocional da depoente, considerada a sua condição peculiar de pessoa em situação de violência doméstica e familiar;

II - garantia de que, em nenhuma hipótese, a mulher em situação de violência doméstica e familiar, familiares e testemunhas terão contato direto com investigados ou suspeitos e pessoas a eles relacionadas;

III - não revitimização da depoente, evitando sucessivas inquirições sobre o mesmo fato nos âmbitos criminal, cível e administrativo, bem como questionamentos sobre a vida privada. 
Dentre as ações do GAVV da UNISEG 4 temos:

I - Visita, apoio, orientação e cuidado às mulheres vítimas de violência doméstica na comunidade, bem como àquelas submetidas a medidas protetivas (Ronda Maria da Penha). II - Visita, apoio, orientação e cuidado aos familiares de vítimas de crimes contra a vida. III - Visita, apoio, orientação e cuidado às vítimas de crimes que causem grande clamor social. IV - Interlocução com outros atores de prevenção social e repressão qualificada que atuam no território (Alencar, Moura, \& Freitas, 2017, p. 30).

A viatura possui um telefone funcional, para o qual a vítima atendida pelo GAVV pode ligar caso necessite e a viatura se desloca para sua residência imediatamente. Se as demandas surgirem fora dos dias e horários de atendimento do GAVV, elas são prontamente recepcionadas pelas viaturas de patrulhamento e atendimento de emergência.

As demandas/ocorrências chegam à equipe por meio: a) do P4 (estatísticas do batalhão); b) de ocorrências de campo; c) do juizado (medidas protetivas); d) de denúncias da população; e e) de informações repassadas pelo patrulhamento da área.

Cabe destacar que, na primeira visita da viatura à casa da vítima, preenche-se um Prontuário de Atendimento à Pessoa, no qual constam os dados pessoais da vítima e do agressor (como endereço, se possui medida protetiva, se a vítima ou o agressor são usuários de droga). Mostra-se de fundamental importância que o redator informe os principais pontos explanados na conversa para que qualquer pessoa que porventura precise saber dos detalhes do caso não peça que a vítima relate novamente toda a história.

Depois de preencher o prontuário, a equipe do GAVV passa a acompanhar aquela pessoa em situação de violência. Não há uma rotina pré-estabelecida quanto ao número de visitas e quais vítimas serão visitadas naquele dia. O trabalho da polícia não é "engessado": todos os dias, ocorrem situações que necessitam de apoio policial. Desse modo, a equipe analisa a gravidade da situação que a vítima está vivenciando, por exemplo, em alguns casos a viatura passa na residência da vítima todos os dias, em outros casos a frequência das visitas é menor.

O grupo também elabora o Relatório de Identificação de Demanda Social (RIDS), que tem o propósito de melhorar a área de atuação da UNISEG. Quando a viatura se depara com lixo na rua ocasionando mau cheiro, falta de iluminação e saneamento básico, algum local que possa mostrar-se propício à ocorrência de delitos, entre outros, a equipe elabora o RIDS e repassa para o setor administrativo do batalhão para que possa realizar os devidos encaminhamentos e sanar o problema. 
Freitas (2017b) menciona que o policial militar tem o dever legal de atuar em qualquer demanda que exija sua intervenção. Logo, as viaturas do GAVV realizam a patrulha pelas ruas dos bairros como quaisquer outras viaturas policiais. Se a composição se deparar com qualquer situação de emergência, de imediato fará a intervenção. Almeida, Moura e Freitas (2017b) ressaltam que "o Policiamento Comunitário não é condescendente com o Crime", ou seja, ele responde às chamadas e efetua prisões como quaisquer outras forças policiais e age dentro da lei. Além das visitas diárias, sua equipe realiza abordagens rotineiras a pessoas que apresentem atitudes suspeitas, proporciona apoio às demais viaturas da área, realiza saturações nos bairros, atende ocorrências de campo e patrulha a área.

A 4ํ. UNISEG é uma ação do Pacto "Por um Ceará Pacífico" (2015) que amplia os serviços prestados e reforça o efetivo de policiais nos bairros Bom Jardim, Granja Lisboa e Siqueira desde novembro de 2017. Seu objetivo é garantir segurança e tranquilidade aos moradores via trabalho integrado entre PCCE, PMCE, AESP, CBMCE e PEFOCE em uma área geográfica reduzida e coincidente.

Assim, a 4a - UNISEG trabalha o policiamento comunitário de modo próximo à população e amplia os serviços das forças de segurança integrando a 32a Delegacia de

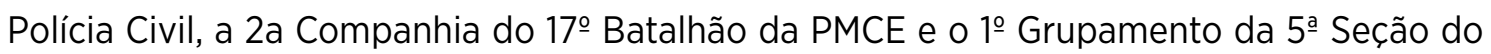
Quartel do CBMCE. O território de atuação diminuiu - passou de 4 bairros para 3.

Em relação à PMCE: antes eram 119 policiais para 4 bairros e apenas 3 viaturas. Com a implementação da UNISEG existem 254 policiais, 10 viaturas e 9 motos para policiamento e 1 base móvel comunitária.

Em relação à PEFOCE: antes eram apenas serviços de periciais, mas, com o advento da UNISEG, eles priorizam as ações de polícia técnico-científica e a capacitação dos profissionais de segurança pública que atuam no território da UNISEG.

Em relação à PCCE: antes o funcionamento das delegacias ocorria em horário de expediente (dias úteis, de segunda a sexta-feira), contando com 1 delegado, 4 escrivães, 14 inspetores e 3 viaturas. Depois da instalação da UNISEG, o funcionamento ocorre 24 horas, 7 dias por semana, inclusive aos sábados, domingos e feriados, contando com 6 delegados, 12 escrivães, 23 inspetores e 5 viaturas.

E, por fim, em relação ao CBMCE: antes existia apenas o serviço de emergência, mas, com advento da UNISEG, houve intensificação das vistorias, dos projetos sociais e dos serviços de emergência. 


\section{A atuação do Grupo de Apoio às Vítimas de Violência na $4^{\mathrm{a}}$ Unidade Integrada de Segurança Durante a Pandemia de covid-19}

O GAVV atua na 2 ${ }^{\text {a }}$ Companhia do 17ํㅡatalhão da PMCE e compreende o território da UNISEG 4, atuando nos bairros Siqueira, Granja Lisboa e Bom Jardim em Fortaleza; atende, em especial, mulheres vítimas de violência doméstica. Ressalta-se que, a princípio, seria levantado o perfil das mulheres atendidas pelo GAVV, porém, isso não foi possível, pois alguns dados são sigilosos.

A filosofia de polícia comunitária vem ganhando força em todo o mundo, produzindo resultados positivos nos locais onde é aplicada e mostrando-se uma importante ferramenta dos órgãos de segurança pública em suas estratégias contra o crime. Considerado de grande relevância e importância para a preservação da ordem pública, o tema deve ser constantemente abordado nos debates sobre estratégias de segurança pública (Joubert \& Thiesen, 2016).

O telefone funcional da viatura é uma ferramenta indispensável para a atuação do GAVV - em alguns momentos, quando a vítima que está sendo atendida se sente ameaçada ou precisa da presença da polícia com rapidez para sanar o problema, ela entra em contato diretamente com os policiais do grupo e a viatura realiza deslocamento com a maior brevidade possível. Há uma relação de confiança entre a polícia e a sociedade. Em todas as visitas se repete o número de telefone da viatura.

A rede socioassistencial é uma "oferta pública de uma rede continuada de serviços, programas, projetos e benefícios de assistência social mediante articulação entre todas as unidades de provisão do [Sistema Único de Assistência Social (SUAS)]". A Lei n. 8.742 (Lei Orgânica da Assistência Social [LOAS], 1993), ressalta em seu art. 1o que a assistência social é

[...] direito do cidadão e dever do Estado, é Política de Seguridade Social não contributiva, que provê os mínimos sociais, realizada através de um conjunto integrado de ações de iniciativa pública e da sociedade, para garantir o atendimento às necessidades básicas.

O SUAS é um sistema público que organiza os serviços de assistência social no Brasil. Possui modelo de gestão participativa e articula os esforços e os recursos municipais, estaduais e federais. Apresenta 2 tipos de proteção social: 
1. A primeira é a proteção social básica, destinada à prevenção de riscos sociais e pessoais, com ofertas de programas, projetos, serviços e benefícios a indivíduos e famílias em situação de vulnerabilidade social;

2. A segunda é a proteção social especial, destinada a famílias e indivíduos que já se encontram em situação de risco e que tiveram seus direitos violados em decorrência de abandono, maus-tratos, abuso sexual, uso de drogas, etc (PNAS, 2009).

A polícia não pode trabalhar sozinha - a atuação tanto da comunidade quanto das redes socioassistenciais existentes é algo muito importante. Lehmkuhl e Carlos (2016) afirmam que a prevenção da criminalidade e o controle da violência dependem de um conjunto de esforços e da integração de diversos órgãos, devendo estes passar a atuar de modo preventivo.

A relação da PMCE com essa rede socioassistencial se mostra bem positiva, como ilustra a fala abaixo - quando a polícia enxerga uma situação que não se enquadra em suas competências, seu dever é repassar as demandas para os órgãos competentes. A polícia é uma ponte que liga a sociedade a essa rede assistencial.

Acho que é boa, né, a relação é boa, acho que nunca ficou faltando nada, não, de quem solicitou o que a gente pediu. (Entrevistado 2)

Para isso, primeiro, os policias precisam tomar conhecimento da rede e saber com o que cada órgão atua para realizar os encaminhamentos necessários. A intersetorialidade, segundo Cavalcanti, Batista e Silva (2013),

[...] é a articulação entre as políticas públicas por meio do desenvolvimento de ações conjuntas destinadas à proteção social, inclusão e enfrentamento das expressões da questão social. Supõe a implementação de ações.

O GAVV também conta com o apoio dos profissionais que fazem parte do Pacto "Por um Ceará Pacífico" (2015), que também atuam na mediação entre a sociedade e a rede socioassistencial. Quando a relação com o familiar está muito restrita à polícia, a equipe repassa o caso para o Pacto "Por um Ceará Pacífico" (2015), que consiste em pessoas que têm acesso aos bairros para solucionar as demandas. O essencial é zelar pela integridade física, moral e social dos envolvidos.

A Casa da Mulher Brasileira, recentemente implementada em Fortaleza, representa um marco na luta em defesa da mulher. Os profissionais do GAVV sempre estão em contato com as equipes multiprofissionais que atendem em casa para estreitar essa relação. 
Durante a pandemia de COVID-19, o policiamento preventivo da PMCE apresentou algumas reconfigurações, uma vez que essa atividade envolve intenso contato com as pessoas, no acompanhamento às vítimas de violência e nos demais modos de relacionamento com as comunidades.

De acordo com o Decreto Estadual n. 33.519 (2020), à medida que foram intensificando-se as medidas para o enfrentamento da COVID-19 houve necessidade de adequar a manutenção das atividades proativas por meio do policiamento preventivo especializado, para garantir a segurança dos públicos atendidos pelas modalidades do policiamento direto.

Neste momento, o GAVV e as outras modalidades de policiamento foram mantidos. Os serviços disponíveis foram prestados com priorização do contato remoto e minimização do contato físico com o público assistido, de modo que somente nos casos onde os riscos não puderam ser superados remotamente, o policiamento manteve contato físico com o público assistido e, nesses casos, o policiamento deve respeitar as barreiras necessárias para a não proliferação da COVID-19.

As escalas de serviço foram executadas de segunda-feira a domingo, em turnos de 8 horas, e as equipes alternaram as jornadas de serviço de modo a dispor de pelo menos 1 equipe do policiamento proativo por dia - a escala deve ter 1 ciclo de 2 serviços de 8 horas, em dias consecutivos e 2 dias seguidos de folga $(2 \times 2)$. Deve-se assegurar o prontoatendimento a eventuais demandas surgidas por meio desses canais de comunicação.

Além disso, cabe destacar que a principal atividade de tal policiamento foi a fiscalização do cumprimento das medidas restritivas, estabelecidas pelo Decreto Estadual n. 33.519 (2020), que intensifica as medidas para enfrentamento da COVID-19.

Durante a pandemia de COVID-19, as equipes do GAVV devem acompanhar remotamente as pessoas atendidas por seus serviços, sobretudo os idosos, as crianças e as mulheres, que, devido à sua situação de vulnerabilidade, necessitem da manutenção de contato telefônico ou mediada por outra tecnologia que lhes assegure o exercício de seus direitos e de suas garantias.

\section{Considerações finais}

Este artigo apresentou as UNISEG enfocando os bairros Bom Jardim, Siqueira e Granja Lisboa em Fortaleza, sob a responsabilidade do 17을atalhão da PMCE.

A violência doméstica e familiar é fruto de um processo histórico de construção social, material e simbólica da ideologia de superioridade do homem em relação à mulher. A PMCE oferece um serviço de aproximação, cuidado, acolhimento e proteção de mulheres vítimas de violência doméstica e familiar, orientado pela filosofia de polícia comunitária 
(Freitas, 2017b). Muitas vezes, esse tipo de violência ocorre de modo silencioso e destruidor, constituindo um fenômeno complexo e multicausal.

A Lei Maria da Penha (2006) é de longe o maior e mais significativo passo que o Estado brasileiro deu para tutelar o equilíbrio entre as relações de gênero. Portanto, como menciona Silva (n.d.), essa lei assumiu vital relevância por efetivar maneiras de punição aos agressores, além de criar medidas protetivas para garantir a integridade física e psicológica da vítima.

Nesse sentindo, constata-se a importância da polícia comunitária, uma ferramenta de adequação do exercício da autoridade policial. Ela se apresenta como uma alternativa teórica necessária ao processo de transmutação das práticas policiais, exigindo das instituições de segurança pública a substituição do emprego inadequado da força como prioridade na resolução de conflitos por práticas que coloquem a comunidade no centro dos processos de identificação, análise, resposta e avaliação das melhores estratégias de garantia da própria segurança.

O policiamento comunitário materializa esses princípios, consistindo na adequação de práticas organizacionais e operacionais com vistas a aperfeiçoar o emprego da força policial, manifestado pela presença, atuação e disponibilidade dos agentes de segurança sob uma lógica de aproximação, conhecimento e confiança estabelecida entre o cidadão (usuário dos serviços de segurança pública) e o Estado (provedor dos serviços de segurança pública).

\section{Referências bibliográficas}

Agência Patrícia Galvão. (2016). Por que as taxas brasileiras são alarmantes? Recuperado de https:// dossies.agenciapatriciagalvao.org.br/feminicidio/capitulos/qual-a-dimensao-do-problema-nobrasil/

Alencar, J. W. A., Moura, V. C., \& Freitas, J. M. M. (2017). Doutrina de Polícia Comunitária (Curso de Formação Profissional para a Carreira de Praças Policiais Militares do Ceará). Fortaleza, CE:

Academia Estadual de Segurança Pública.

Bohn, M. F. (n.d.). Policiamento comunitário: a transição da polícia tradicional para a polícia cidadã. Recuperado de http://ebooks.pucrs.br/edipucrs/anais/cienciascriminais/IV/54.pdf

Brasil, M. G. M., \& Miranda, A. K. P. (2011, setembro). Polícia e mediação de conflitos: o que muda na formação policial? In Anais do 28ㅜ Congresso Internacional da Asociación Latinoamericana de Sociología. Recife, PE.

Cavalcanti, P. B., Batista, K. G. S., \& Silva, L. R. (2013). A estratégia da intersetorialidade como mecanismo de articulação nas ações de saúde e assistência social no município de Cajazeiras-PB. Recuperado de ebooks.pucrs.br/edipucrs/anais/sipinf/edicoes/l/9.pdf 
Centro de Estudos sobre o Sistema de Justiça. (2012). A violência doméstica fatal: o problema do feminicídio íntimo no Brasil. Recuperado de http://www.compromissoeatitude.org.br/dadosnacionais-sobre-violencia-contra-a-mulher/ Constituição da República Federativa do Brasil, de 5 de outubro de 1988. (1988). Brasília, DF. Constituição dos Estados Unidos do Brasil, de 18 de setembro de 1946. (1946). Rio de Janeiro, DF. Decreto Estadual n. 31.840, de 25 de novembro de 2015. (2015). Pacto "Por um Ceará Pacífico". Fortaleza, CE.

Decreto Estadual n. 33.519, de 19 de março de 2020. (2020). Intensifica as medidas para enfrentamento da infecção humana pelo novo coronavírus. Fortaleza, CE.

Freitas, J. M. M. (2017a). Polícia comunitária: uma construção jurídica que se opõe à ideia de uma polícia de autoridade fragilizada. Recuperado de https://direitodiario.com.br/6865-2/

Freitas, J. M. M. (2017b). Violência contra a mulher: polícia comunitária como instrumento de eficácia das medidas de prevenção integrada, assistencial e de urgência da Lei Maria da Penha (Monografia de Graduação). Universidade Federal do Ceará, Fortaleza, CE.

Freitas, J. M. M., \& Parente, D. O., Júnior. (2016). A Unidade Integrada de Segurança (UNISEG) como instrumento de eficiência na garantia do direito fundamental à segurança pública (Manuscrito não publicado).

Gasman, N. Para o Brasil, há mulheres e mulheres. E todas devem ser controladas. ONU Mulheres, 2014. Recuperado de http://www.onumulheres.org.br/noticias/07-04-2014-para-o-brasil-hamulheres-e-mulheres-e-todas-devem-ser-controladas/

Gil, A. C. (2008). Métodos e técnicas de pesquisa social. São Paulo, SP: Atlas.

Godoy, A. S. (1995). Introdução à pesquisa qualitativa e suas possibilidades. Revista de Administração de Empresas, 35(2), 57-63.

Governo do Estado do Ceará. (n.d.). Ceará Pacífico em ação: matriz de acompanhamento. Fortaleza, CE: Autor.

Joubert, R., \& Thiesen, R. (2016). Polícia comunitária: estabelecendo um novo modelo de polícia. Recuperado de https://jus.com.br/artigos/51568/policia-comunitaria-estabelecendo-um-novomodelo-de-policia/3

Lehmkuhl, C., \& Carlos, L. R. (2016). Polícia contemporânea: nova forma de se pensar e fazer segurança pública. Recuperado de www.feneme.org.br/pagina/1000/policia-contemporanea--nova-forma-de-se-pensar-e-fazer-seguranca-publica Lei n. 8.742, de 7 de dezembro de 1993. (1993). Dispõe sobre a organização da Assistência Social e dá outras providências. Brasília, DF. 
Lei n. 11.340, de 7 de agosto de 2006. (2006). Cria mecanismos para coibir a violência doméstica e familiar contra a mulher, nos termos do § 8 do art. 226 da Constituição Federal, da Convenção sobre a Eliminação de Todas as Formas de Discriminação contra as Mulheres e da Convenção Interamericana para Prevenir, Punir e Erradicar a Violência contra a Mulher; dispõe sobre a criação dos Juizados de Violência Doméstica e Familiar contra a Mulher; altera o Código de Processo Penal, o Código Penal e a Lei de Execução Penal; e dá outras providências. Brasília, DF.

Lei Estadual n. 13.407, de 21 de novembro de 2003. (2003). Código Disciplinar da Polícia Militar do Ceará e do Corpo de Bombeiros Militar do Estado do Ceará. Fortaleza, CE.

Madeira, M. Z. A; Costa, R. G. Desigualdades de gênero, poder e violência: uma análise da violência contra a mulher. Revista O Público e o Privado. № 19. 2012. 79 p a 99 p. Recuperado de http://www.seer.uece.br/?journal=opublicoeoprivado\&page=article\&op=view\&path\%5B\%5D=342\& path\%5B\%5D $=502$

Minayo, M. C. S. (Org.). (1994). Pesquisa social: teoria, método e criatividade (Coleção Temas Sociais). Petrópolis, RJ: Vozes.

Núcleo de Estudos da Violência da Universidade de São Paulo. (2009). Manual de policiamento comunitário: polícia e comunidade na construção da segurança. Recuperado de https://nev.prp.usp. $\mathrm{br} /$ publicacao/manual-de-policiamento-comunitrio-polcia-e-comunidade-na-construo-dasegurana/

Paiva, L. F. Almeida, R. A construção do espaço social das mulheres nas instituições policiais. In: Brasil, G. M. (org) A face feminina da Polícia Civil: gênero, hierarquia e poder. Fortaleza: EdUECE, 2008.p. 71-97.

Plano Nacional de Assistência Social (PNAS). Brasília (DF): Ministério do Desenvolvimento Social e Combate à Fome; 2009.

Silva, J. G. (n.d.). Violência doméstica contra a mulher e serviço social: espaço de atuação e intervenção profissional. Recuperado de www.esedh.pr.gov.br/modules/inscrit_quest/uploads/8/23032016160341_AS_POSSIVEIS_INTERVENCOES_PROFISSIONAIS_NAS_QUESTOES_DA_ VIOLENCIA_DOMESTICA_CONTRA_MULHER.pdf

Unasus. Organização Mundial de Saúde declara pandemia do novo Coronavírus. Publicado em 11/03/2020. Recuperado de https://www.unasus.gov.br/noticia/organizacao-mundial-de-saudedeclara-pa 


\section{Para citar este artigo:}

Norma A - ABNT

FROTA, M. H. P.; SOUSA, K. S.; COSTA, R. H. L. A Polícia Comunitária do Ceará e o acompanhamento às vítimas de violência. Conhecer: Debate entre o Público e o Privado, v. 11, n. 26, p. 30-52, 2021.

Norma B - APA

Frota, M. H. P., Sousa, K. S., \& Costa, R. H. L. (2020). A Polícia Comunitária do Ceará e o acompanhamento às vítimas de violência. Conhecer: Debate entre o Público e o Privado, 11(26), 30-52.

\section{Norma C - Vancouver}

Frota MHP, Sousa KS, Costa RHL. A Polícia Comunitária do Ceará e o acompanhamento às vítimas de violência. Conhecer: Debate entre o Público e o Privado [Internet]. 2021 [cited Jan 4, 2021];11(26): 30-52. Available from: https://revistas.uece.br/index.php/revistaconhecer/article/view/4304 